\title{
Possible influence of ultra-fast Kelvin wave on the equatorial ionosphere evening uplifting
}

\author{
H. Takahashi ${ }^{1}$, M. A. Abdu ${ }^{1}$, C. M. Wrasse ${ }^{2}$, J. Fechine ${ }^{1}$, I. S. Batista ${ }^{1}$, D. Pancheva ${ }^{3}$, L. M. Lima ${ }^{4}$, \\ P. P. Batista ${ }^{1}$, B. R. Clemesha ${ }^{1}$, K. Shiokawa ${ }^{5}$, D. Gobbi ${ }^{1}$, M. G. Mlynczak ${ }^{6}$, and J. M. Russell ${ }^{7}$ \\ ${ }^{1}$ Instituto Nacional de Pesquisas Espaciais, INPE, São José dos Campos, SP, Brazil \\ ${ }^{2} I P \& D$, Universidade do Vale do Paraíba, UNIVAP, São José dos Campos, SP, Brazil \\ ${ }^{3}$ Department of Electronic \& Electrical Engineering, University of Bath, Bath, BA2 7AY, UK \\ ${ }^{4}$ Departamento de Fisica, Universidade Estadual de Paraíba, Campina Grande, PB, Brazil \\ ${ }^{5}$ Solar Terrestrial Environmental Laboratory, STEL, Nagoya University, Toyokawa, Aichi, Japan \\ ${ }^{6}$ Atmospheric Sciences Division, NASA, Langley Research Center, Hampton, VA, USA \\ ${ }^{7}$ Center for Atmospheric Sciences, Hampton University, Hampton, VA, USA
}

(Received October 23, 2007; Revised May 12, 2008; Accepted May 30, 2008; Online published May 14, 2009)

Equatorial 3.5-day ultra-fast Kelvin wave was observed in the MLT zonal wind measured by meteor radar at Cariri $\left(7.4^{\circ} \mathrm{S}, 36.5^{\circ} \mathrm{W}\right.$, geomag. $\left.8^{\circ} \mathrm{S}\right)$ and in the stratosphere-mesosphere temperature structures from the TIMED/SABER data. The ionospheric $F$-layer bottom-side virtual height $h^{\prime} F$ and the critical frequency $f_{\mathrm{o}} F_{2}$ observed at Fortaleza $\left(3.9^{\circ} \mathrm{S}, 38.4^{\circ} \mathrm{W}\right.$, geomag. $\left.5^{\circ} \mathrm{S}\right)$ also showed similar oscillation structures, indicating an influence of the Kelvin wave in the $F$ region height and modulation of $\mathbf{E} \times \mathbf{B}$ uplifting during the evening period. Consequently the ionospheric spread $F$ onset time was also modulated in the same period, around 4 days.

Key words: Equatorial ionosphere, mesosphere, planetary waves, Kelvin wave.

\section{Introduction}

The earth's ionosphere presents strong day to day variability. This is known to be mainly caused by day to day variation of the solar UV flux, disturbance dielectric field from magnetosphere-ionosphere coupling related to forcing by solar wind from above and that of the lower atmosphere dynamical activity from below. The influence of the solar wind and magnetic disturbance on the ionosphere has been extensively studied (see, for example, Kikuchi et al., 1996; Fejer and Scherliess, 1998; Abdu et al., 2007 and references therein). The dynamics in the lower atmosphere, tropospheric cloud convections, generation of the gravity waves, planetary waves, and their penetration into the higher altitudes and disturbing the ionospheric $E$ and $F$ regions have also been investigated since 1970 (Forbes, 1996; Pancheva et al., 2002; Fukao, 2006 etc.). Roettger (1981) pointed out the importance of the cloud convections. Forbes (1996) suggested that planetary waves potentially account for significant day-to-day variability of the $F$-region ionosphere. However, direct signatures of coupling from troposphere to ionosphere through the gravity and planetary waves has not been well studied (Lastovicka, 2006).

Some first works which recognized the influence of planetary waves on the ionosphere were Brown and Williams (1971) and Fraser (1977). They showed correlation between stratospheric pressure variation and $E$-region electron density. The quasi-2-day oscillation of the $F$ re-

Copyright (c) The Society of Geomagnetism and Earth, Planetary and Space Sciences (SGEPSS); The Seismological Society of Japan; The Volcanological Society of Japan; The Geodetic Society of Japan; The Japanese Society for Planetary Sciences; TERRAPUB gion electron peak density related to the analogous oscillation of the mesospheric wind system was reported by Pancheva and Lysenko (1988). In the equatorial region Chen (1992) observed 2-day oscillation of the equatorial ionization anomaly. Since then many works pointed out possible connection from the lower atmosphere planetary wave activity and analogous variations in the ionospheric parameters $\left(h^{\prime} F, f_{\mathrm{o}} F_{2}, h_{\mathrm{m}} F_{2}, h^{\prime} E, f_{\mathrm{o}} E_{\mathrm{s}}\right.$, etc.): oscillations of 2-d, 4-d, 6-d, 16-d (Forbes and Leveroni, 1992; Haldoupis et al., 2004; Takahashi et al., 2005). Forbes et al. (2000) estimated that the influence of tropospheric activity could produce day to day variability (2-30-days) in the ionosphere that could correspond to a variation of up to $15-20 \%$ of the $F$-region peak plasma density. Further recent works investigate interaction of the tides and planetary wave in the lower ionosphere, and resulting modulation in the $E$-layer (Haldoupis et al., 2004).

In the equatorial region, there are three kind of planetary scale waves, Kelvin, Rossby normal mode and Rossby gravity waves. Kelvin waves are, different to the others, trapped in the equatorial region $\left( \pm 10-15^{\circ}\right)$ and the phase propagating toward east. Kelvin waves have three different periods, slow ( $\sim 16$ days), fast ( $\sim 6$ days) and ultra fast (34 days). The ultra-fast Kelvin wave (hereafter UF-Kelvin wave) has the horizontal wavelength of $\sim 40,000 \mathrm{~km}$ (wave number 1), vertical wavelength of $40-60 \mathrm{~km}$, and horizontal phase velocity of $120-150 \mathrm{~m} / \mathrm{s}$ (Forbes, 2000). Presence of the UF-Kelvin wave in the equatorial middle atmosphere was first reported by Salby et al. (1984) in the stratosphere and then by Vincent (1993) from the mesospheric wind structures, and later by Lieberman and Riggin (1997) who used UARS satellite wind data. Riggin et 
al. (1997) also investigated by using ground based MF and meteor radars. Then several works regarding the UF-Kelvin wave characteristics observed from MF radars (Sridharan et al., 2002) and meteor radars (Younger and Mitchell, 2006) have also been reported. From the ground based airglow observation Takahashi et al. (2002) reported 3-4 day period oscillation of the mesospheric airglow and $\mathrm{OH}$ temperature variations. Lichstein et al. (2002) presented the amplitude of mesospheric airglow oscillation and estimated that the amplitude of oscillation in the temperature reached about $6 \mathrm{~K}$ when the wave passed in the $\mathrm{OH}$ emission layer. Signatures of the UF-Kelvin wave in the ionosphere were recently reported by Takahashi et al. (2007). Due to a high horizontal phase velocity $(\sim 130 \mathrm{~m} / \mathrm{s})$ and long vertical wavelength $(30-50 \mathrm{~km})$, this wave can propagate upward without much dissipation. Forbes (2000) showed in his model atmosphere that the UF-Kelvin wave could propagate up to the lower thermosphere producing zonal wind components of $10-40 \mathrm{~m} / \mathrm{s}$ and neutral atmosphere temperature of $10-25 \mathrm{~K}$ in the $100-150 \mathrm{~km}$ height region. Miyoshi and Fujiwara (2006) demonstrated in their general circulation model that the UF-Kelvin wave could propagate upward to the lower thermosphere. Quantitative observations, i.e., amplitude and phase of the wind velocity and the temperature field, are necessary for further investigations.

The present study, therefore, focuses on the discussion to find out evidence of the UF-Kelvin waves, wave characteristics, height structure, phase and amplitude. In the previous work by Takahashi et al. (2007) the presence of UFKelvin waves in the upper mesosphere and possible penetration into the ionosphere were discussed. In the present work, further investigation of the UF-Kelvin waves was carried out by using the TIMED/SABER temperature data in a global scale, in addition to the meteor wind data using a whole year of 2005. These parameters as well as the $F_{2}$ layer evening uplift $\left(h^{\prime} F\right)$ were subjected to wavelet spectral analysis. Then we investigate day-to-day variability of the $F_{2}$ layer evening uplift which controls the spread $F$ onset time.

\section{Observations}

A SkiYmet meteor radar is in operation at Sao Joao do Cariri $\left(7.4^{\circ} \mathrm{S}, 36.5^{\circ} \mathrm{W}\right.$, geomag. $\left.8^{\circ} \mathrm{S}\right)$, hereafter Cariri, since June 2004. This is a pulsed radar, transmission power of 12 $\mathrm{kW}$, operating at $35.2 \mathrm{MHz}$ with an interferometric receiver antenna array. The zonal and meridional wind components are calculated in one-hour time bins for 7 atmospheric layers with a $3 \mathrm{~km}$ interval from 80 to $100 \mathrm{~km}$ of altitude. Data processing and the other radar information have been presented elsewhere (Lima et al., 2004). Ionospheric parameters were measured at Fortaleza $\left(3.9^{\circ} \mathrm{S}, 38.4^{\circ} \mathrm{W}\right.$, geomag. $5^{\circ} \mathrm{S}$ ) by a Digital ionospheric sounder (DPS-4). This is a wide-band coded pulsed radar system with $500 \mathrm{~W}$ peak power and a precise fast-switching frequency synthesizer, covering a frequency range from 0.5 to $30 \mathrm{MHz}$. Ionograms are taken with a 10 -min observational cadence. The ionospheric parameters used in this work are the critical frequency of the $F_{2}$ layer, $f_{\mathrm{o}} F_{2}$, and the minimum virtual height, $h^{\prime} F$. Fortaleza is located at $450 \mathrm{~km}$ northwest of Cariri, and both are in a same local time zone.
The TIMED (Thermosphere Ionosphere Mesosphere Energetics and Dynamics) satellite has been in operation since 2002 and its SABER (Sounding of the Atmosphere using Broadband Emission Radiometry) instrument measures atmospheric neutral temperature from 10 to $130 \mathrm{~km}$ of altitude (Russell et al., 1999). In the present work the level 2A kinetic temperature data (version 01.06 of 2005) from 30 to $120 \mathrm{~km}$ were used. The precision of temperature retrieve is $1 \mathrm{~K}$ below $80 \mathrm{~km}$ and $2 \mathrm{~K}$ above $80 \mathrm{~km}$. In order to find a representative temperature for a given day and location, the temperature profiles are grouped in a time bin of $24 \mathrm{~h}$ and an area of $20 \times 20$ degrees along the geographic equator zone. In this way at least 10 temperature profiles were used to get a daily mean profile for each longitudinal zone.

\section{Results}

\subsection{Wavelet analysis of wind, $h^{\prime} F$ and $f_{0} F_{2}$}

Equatorial Kelvin waves have burst like and short duration ( 2 to 5 crests) characteristics followed by their disappearance (Lastovicka, 2006; Younger and Mitchell, 2006). In order to find out their oscillations in a long period time series, we have used Wavelet spectral analysis in this study. In Fig. 1 Morlet wavelet power spectrum of the mesospheric zonal wind at $90 \mathrm{~km}$ observed at Cariri in 2005 is shown. It can be seen that there are several groups of $\sim 4$ day period oscillations along the year. Among them an oscillation group at around days 60-70 is the most prominent one. The lower panel of Fig. 1 shows 3-5 day filtered phase and amplitude of the zonal wind oscillation at $90 \mathrm{~km}$. The first event (days 60-70) has an amplitude of $30 \mathrm{~m} / \mathrm{s}$, lasting 3 oscillations which then decreased. The second event can be seen between days 190-220. During this period there are two peaks of oscillation, one at around day-190 and the other around day-210. Both the peaks have an amplitude of $20 \mathrm{~m} / \mathrm{s}$. Background wind was around $-15 \mathrm{~m} / \mathrm{s}$ (westward) during the first event (days 60-70). During the second event (days 190-210), the background wind changed the direction from eastward $(+10 \mathrm{~m} / \mathrm{s})$ to westward $(-10 \mathrm{~m} / \mathrm{s})$. Comparing the magnitude of the background wind, the observed amplitudes of the 4-day oscillation are relatively large. From the phase and amplitude variations (the bottom side panel of Fig. 1) one can also see $\sim 4$-day oscillations at around days 240-260 and days 290-330. During these periods, however, a strong 6 day oscillation (the former) and a 6-8 day oscillation (the latter) were observed. Therefore the $\sim 4$ day oscillations might be covered by these longer period oscillations, and this makes it difficult to analyze the wave characteristics. These $\sim 6$ day and $6-8$ day oscillations are worthwhile to investigate, but it is beyond of our present work.

Wavelet analysis of day to day variability of the $F$-layer bottom-side virtual height, $h^{\prime} F$ observed at Fortaleza in 2005 is shown in Fig. 2. The data between day-120 and day180 are missing in the present analysis. At the geomagnetic equatorial region the $F$-layer is uplifted at sunset by the $F$ region dynamo eastward electric field. In order to see the day to day variability of this effect we chose $h^{\prime} F$ at a fixed local time. In the present study $h^{\prime} F$ at 2000 LT (2300 UT) when it reaches the maximum height on most of the night was used. During the period from day-50 to day-90 a strong 

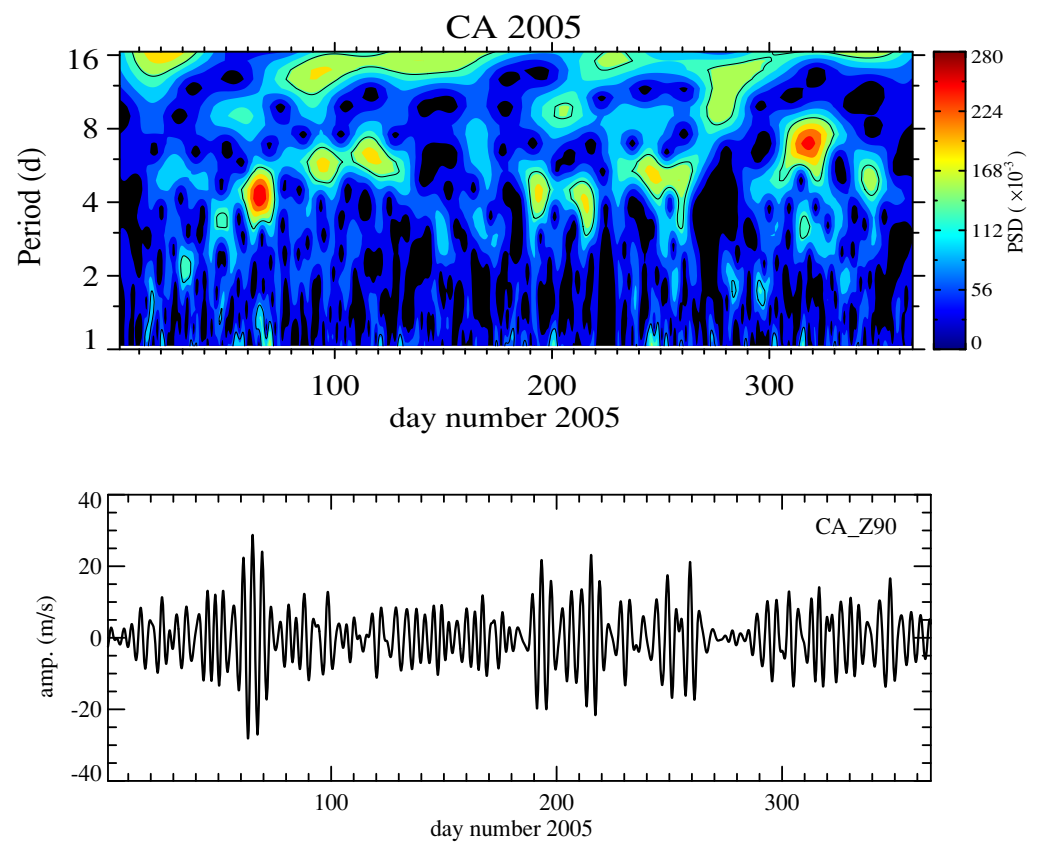

Fig. 1. Wavelet power spectrum of the mesospheric zonal wind at $90 \mathrm{~km}$ (upper panel) and 3-5 day filtered phase and amplitude (lower panel) along the year from January to December 2005 over Cariri (7.4 S, $35.6 \mathrm{~W})$.
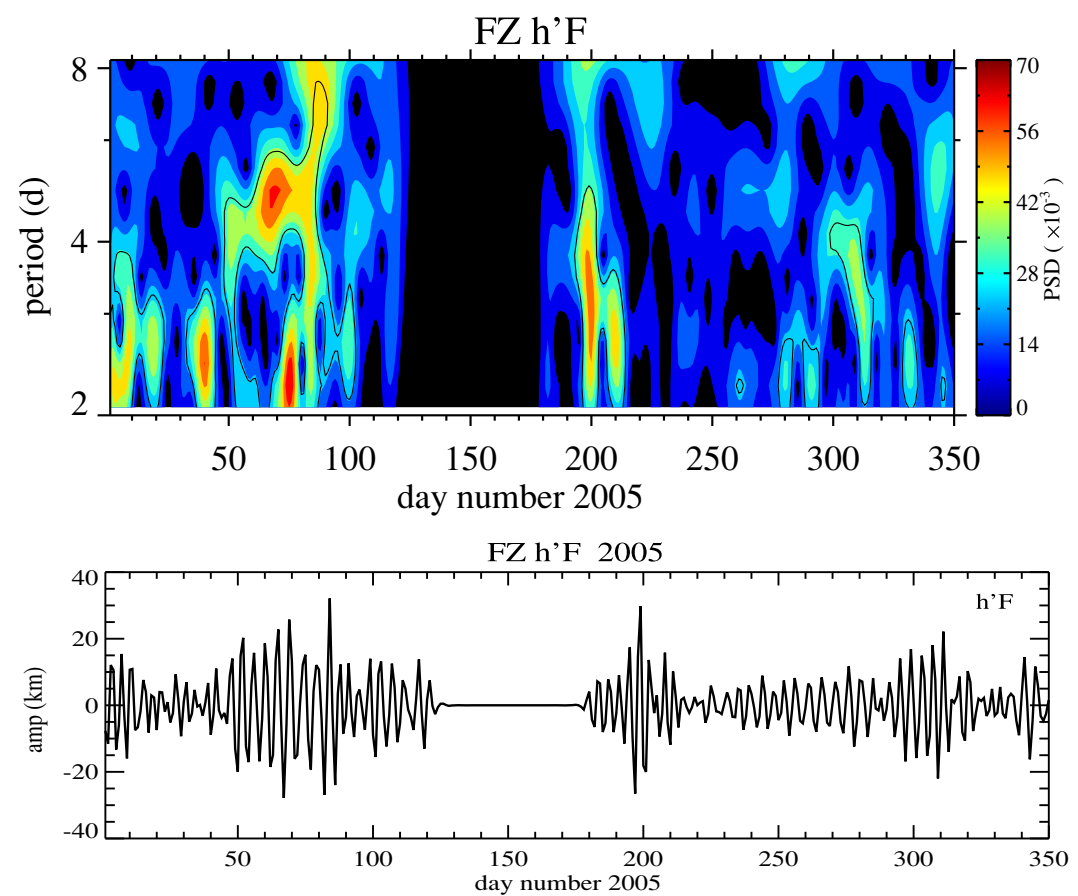

Fig. 2. Wavelet power spectrum of the ionospheric $F$-layer bottom-side virtual height $h^{\prime} F$ (upper panel) and 3-5 day filtered phase and amplitude spectrum (lower panel) observed at Fortaleza (3.9 S, $38.4 \mathrm{~W}$ ) in 2005. The data between day-120 and day-180 are missing.

4-5-day oscillation can be noted. The strong oscillation with the amplitude of $25 \mathrm{~km}$ is located at around days 6070. The next $\sim 4$-day oscillation is located at around days 190-210. Both of the events show the wavelet power spectrum with the $95 \%$ confidence level (Torrence and Compo, 1998). Similar analysis was applied for $f_{\mathrm{o}} F_{2}$ and the result is shown in Fig. 3. During the period of days 60-70, again, one can see $\sim 4$-day oscillation feature with an amplitude of $0.8 \mathrm{MHz}$. Similar oscillation feature (3-5-day period) can also be seen during days 200-220 with the amplitude of $\sim 1.0 \mathrm{MHz}$. There is a much stronger oscillation feature during the period of days 230-250. This must be related to the geomagnetic activity which occurred during the same period. In Fig. 4 geomagnetic $A_{\mathrm{p}}$ index in 2005 is shown as a reference. Strong magnetic activity was observed in January (days 15-25), May (days 130-150) and AugustSeptember (days 230-260). The two $\sim 4$-day period oscillation events, one at days 60-70 and the other at days 190210 , are free from these geomagnetic activity events. 

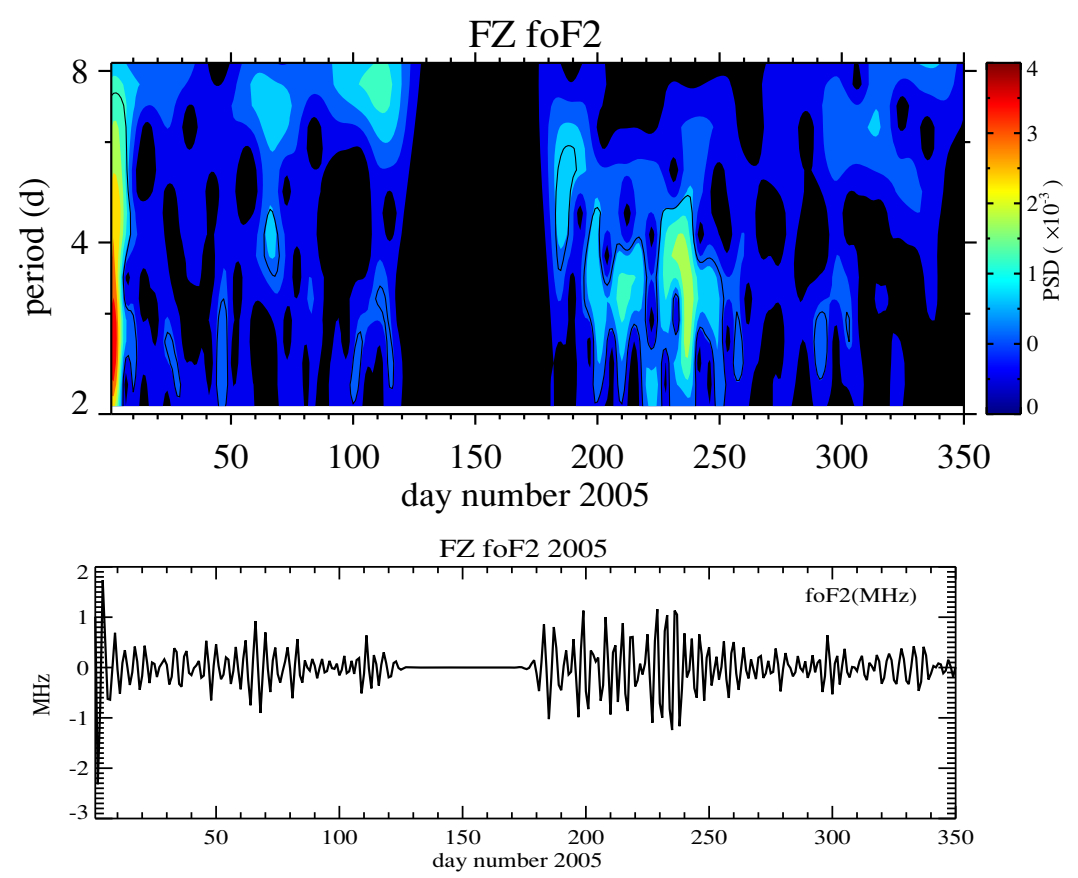

Fig. 3. Same as Fig. 2, except for the $F$-layer critical frequency $f_{\mathrm{o}} F_{2}$.

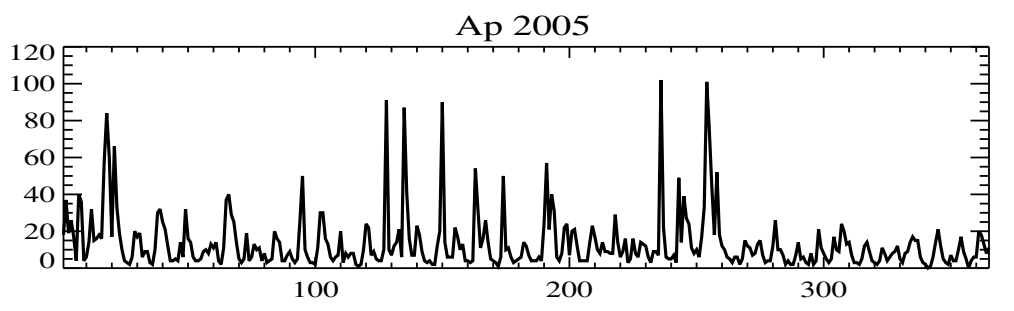

Fig. 4. Geomagnetic activity $A_{\mathrm{p}}$ (3 hourly) index in 2005.

\subsection{Wave characteristics of the $\sim 4$ day oscillations from the wind and SABER data}

In order to study the characteristics of the observed 3-5day oscillation we checked vertical phase propagation mode in the mesospheric zonal winds. In Fig. 5 the phase of the maximum of the 3.5-day period wind component for the period of days 59-70 is shown as a function of height from 81 to $99 \mathrm{~km}$. The downward phase propagation mode indicates that the vertical wavelength is around $39 \pm 5 \mathrm{~km}$. For the second event (days 190-210) also a similar result was obtained, but with a rather longer vertical wavelength $84 \pm 10 \mathrm{~km}$. This could be due to background wind structure (Doppler effect) during the period as mentioned in the previous section.

The presence of a 3-5-day period wave can also be seen in the TIMED/SABER temperature data. From the daily mean temperature time series over the Cariri area $(20 \times$ 20 degrees) we calculated 3-5-day filtered oscillation amplitude and phase for different altitude from 30 to $130 \mathrm{~km}$. The results are shown in Fig. 6 for 40, 60, 80, 100 and $120 \mathrm{~km}$ altitude. During the first event (days 60-70), marked by a rectangular box, a large temperature field perturbation can be seen at $40 \mathrm{~km}$ with an amplitude of $3 \mathrm{~K}$. The oscillation decreased at $60 \mathrm{~km}$, and appeared at $80 \mathrm{~km}$ with the amplitude of $5 \mathrm{~K}$. The amplitude of oscillation in-

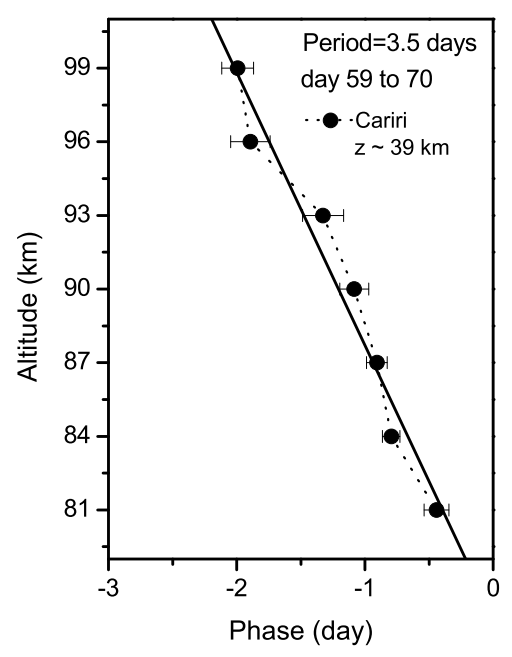

Fig. 5. Phase profile of the Cariri zonal wind from 80 to $100 \mathrm{~km}$ of altitude during the period of days 59-70, 2005.

creased to $10 \mathrm{~K}$ at $120 \mathrm{~km}$, indicating that the amplitude increased with height. In the second period (days 190210), also marked by a rectangular box, the temperature field at $40 \mathrm{~km}$ showed an oscillation of $2 \mathrm{~K}$. In the $60 \mathrm{~km}$ height region, the oscillation peak occurred at around day- 


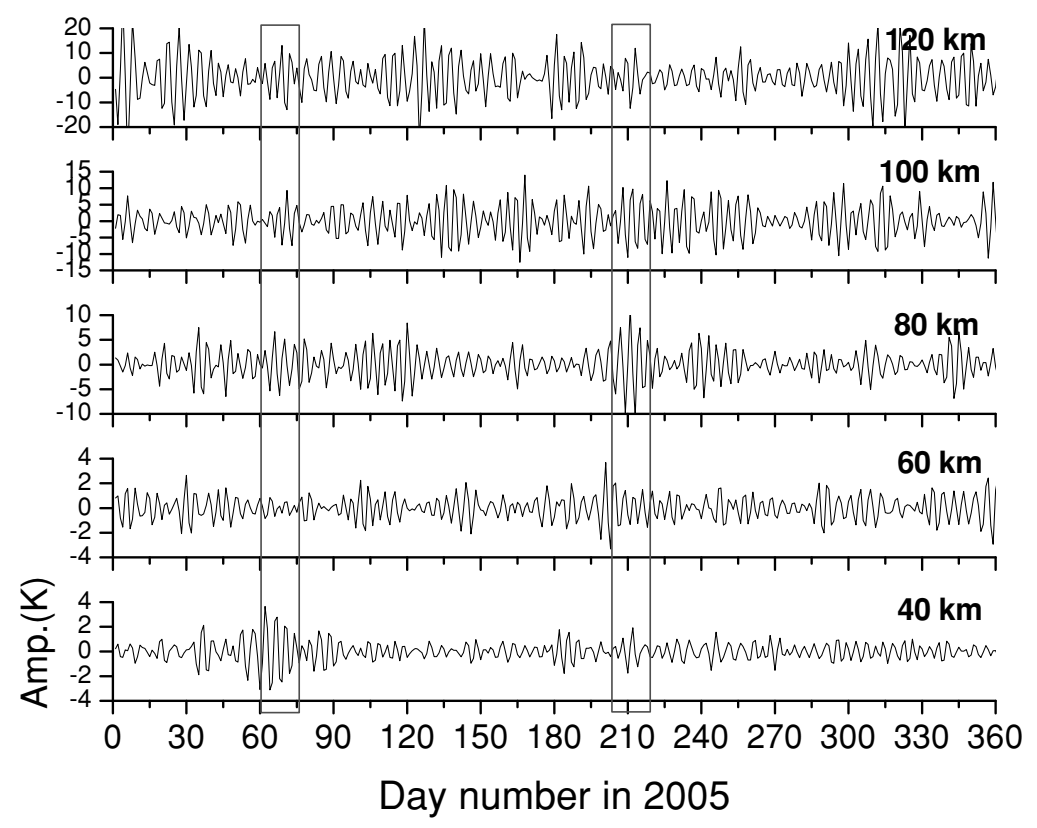

Fig. 6. Phase and amplitude of the 4-day (3-5-day filtered) oscillation of the SABER temperature daily mean values over Cariri in 2005, for different altitudes from 40,60, 80, 100 and $120 \mathrm{~km}$.

190 with the amplitude of $4 \mathrm{~K}$. The oscillation packet at around day-210 is very prominent at $80 \mathrm{~km}$ with the amplitude of $10 \mathrm{~K}$. This oscillation feature propagated up to $120 \mathrm{~km}$ with a same amplitude of oscillation. These results suggest that there were wave packets propagating upward from the stratosphere to lower thermosphere, increasing their amplitude of oscillation from $2 \mathrm{~K}$ at $40 \mathrm{~km}$ to $10 \mathrm{~K}$ at $80-100 \mathrm{~km}$ of altitude. From the phase propagation characteristics between 80 and $100 \mathrm{~km}$ height we calculated the vertical wavelength, to be $34 \pm 2 \mathrm{~km}$. In addition to these two wave packets, there are two more wave packets those have significant amplitude of oscillation in the 80 to $100 \mathrm{~km}$ height regions, i.e., day-110-120 and day-240-250. During these periods, however, no $\sim 4$ day oscillation could be seen in the wind structure, rather covered by strong $\sim 6$ day oscillations. Therefore we did not consider these oscillations as a wave to be considered.

In order to see longitudinal extension of the wave events, we plotted in Fig. 7 the amplitude of the 3-5-day oscillation of the SABER temperature at $90 \mathrm{~km}$ height along the day48 to 88 as a function of longitude. A latitudinal range of \pm 10 degrees was used along the equator. We note clearly that during the period of days $60-70$ the $\sim 4$-day period oscillation is strong and the phase propagates eastward. From the longitudinal phase propagation mode, one can see the wave number 1 with a mean phase velocity of $120 \mathrm{~m} / \mathrm{s}$. It is interesting to note that the amplitude of oscillation is not homogeneous along the longitude. Larger amplitude zones can be seen over Eastern Pacific region $\left(\sim 120^{\circ} \mathrm{W}\right)$, South Atlantic to African sector $\left(0-60^{\circ} \mathrm{W}\right)$ and Indian Ocean sector $\left(60-90^{\circ} \mathrm{E}\right)$.

Concerning the latitudinal extension of the waves, a previous analysis (Takahashi et al., 2007) showed that the $\sim 4$ day oscillation disappeared at $29^{\circ} \mathrm{S}$ indicating that the wave must be one which was trapped in the equatorial region. For the second event (days 190-210) we applied a similar anal-

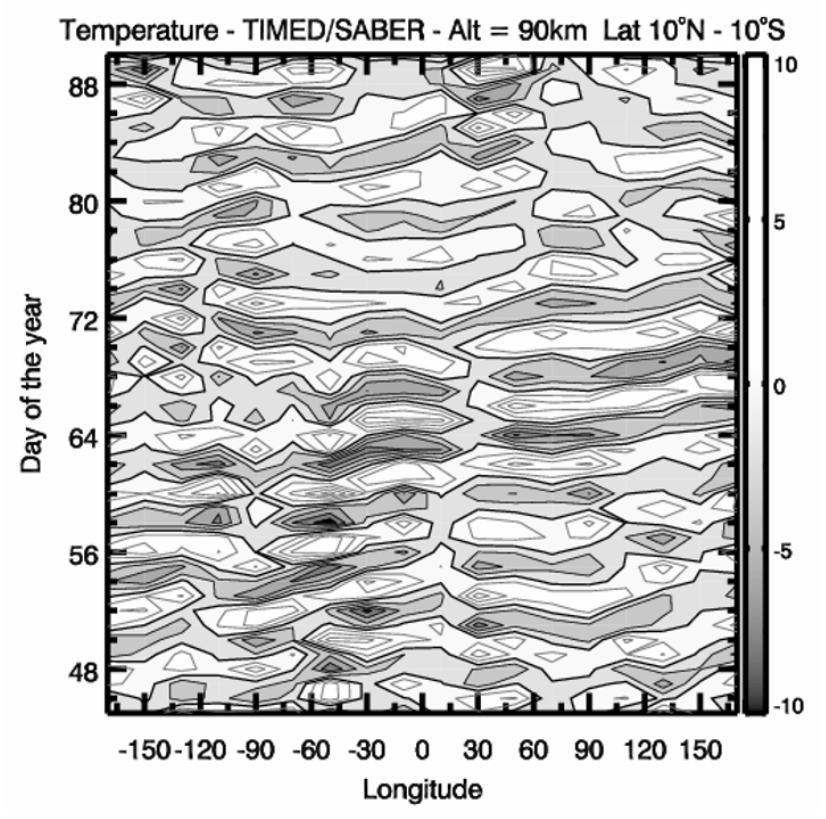

Fig. 7. Longitudinal phase and amplitude structure of the SABER temperature 3-5 day oscillation components at $90 \mathrm{~km}$ of altitude as a function of day of the year (vertical access) from day-48 to 88, 2005.

ysis and found a same result. In Table 1 the observed wave characteristics are summarized. From these wave characteristics we may conclude that the two wave events observed in the mesospheric wind and temperature in 2005 must be the UF-Kelvin wave.

\section{Discussion}

From the mesospheric wind structure at $90 \mathrm{~km}$, the UFKelvin waves were observed in March and July 2005. The stratosphere-mesosphere temperature fields observed 
Table 1. Ultra-fast Kelvin wave characteristics retrieved from the wavelet and harmonic analysis of the mesospheric wind and the stratosphere-mesosphere TIMED/SABER temperatures.

\begin{tabular}{ccc}
\hline & Days 60-70 & Days 190-210 \\
\hline Zonal phase velocity $(\mathrm{m} / \mathrm{s})$ & $\sim 120$ & $\sim 120$ \\
Wave number & 1 & 1 \\
Vertical wavelength $(\mathrm{km})$ & $39 \pm 5$ & $84 \pm 10$ \\
Wind, amplitude at $90 \mathrm{~km}(\mathrm{~m} / \mathrm{s})$ & $30 \pm 3$ & $20 \pm 3$ \\
Temperature, amplitude at $90 \mathrm{~km}(\mathrm{~K})$ & $5 \pm 1$ & $7 \pm 2$ \\
$h^{\prime} F$ (amplitude in $\left.\mathrm{km}\right)$ & $25 \pm 5$ & $30 \pm 5$ \\
$f_{\mathrm{o}} F_{2}$ (amplitude in $\left.\mathrm{MHz}\right)$ & $\sim 0.8$ & $\sim 1.0$ \\
\hline
\end{tabular}

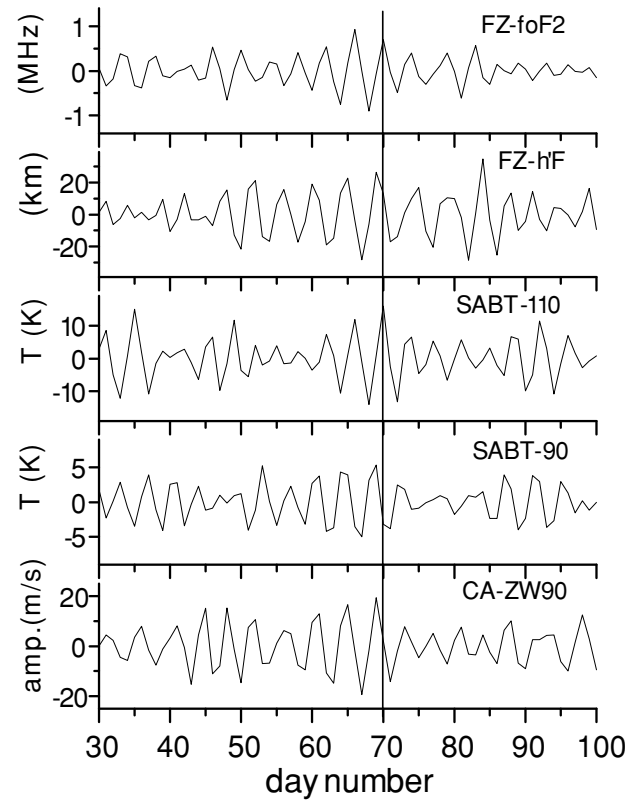

Fig. 8. Phase and amplitude of the 4-day (3-5-day filtered) oscillation of the zonal winds at Cariri, SABER temperature daily means over Cariri, ionospheric $h^{\prime} F$ and $f_{\mathrm{o}} F_{2}$ at Fortaleza in 2005.

by TIMED/SABER also presented the UF-Kelvin wave feature in March and July 2005. Further, the amplitude of the temperature oscillation indicates that the waves propagated up to $120 \mathrm{~km}$ of altitude (Fig. 6). In order to see any coupling feature between the mesosphere and ionosphere, the amplitude and phase of the 3-5 day filtered oscillation of the mesospheric zonal winds, SABER temperatures, and ionospheric $h^{\prime} F$ and $f_{\mathrm{o}} F_{2}$ for the period of days 30-100, are plotted in Fig. 8. The zonal wind at $90 \mathrm{~km}$ and SABER temperature at $90 \mathrm{~km}$ are in phase, but they are in advance ( $\sim 1$ day) to the temperature variation at $110 \mathrm{~km}$. It is interesting to note that the phase of the SABER temperature at $110 \mathrm{~km}$ is in phase with $f_{\mathrm{o}} F_{2}$ and $h^{\prime} F$, what indicates a common oscillation process. These facts strongly suggest that the observed 3-5-day oscillation of $h^{\prime} F$ and $f_{\mathrm{o}} F_{2}$ should be caused by the 3.5-day UF-Kelvin wave. From the present limited data, we could not see any seasonal dependency of the Kelvin wave appearance in the mesosphere and lower thermosphere.

During the local evening time in the equatorial ionosphere, the $F$-layer undergoes rapid uplift. Thermospheric zonal winds change the direction from westward during the daytime to eastward in the evening sector, producing po- larization electric field through thermospheric dynamo process. The polarization electric field $E_{z}$ is downward and has a gradient along the longitudinal direction across the terminator into the night side due to the variation of integrated conductivities of the $E$ - and $F$-region. Denoting the integrated conductivities as $\Sigma_{E}$ and $\Sigma_{F}$, respectively, the vertical electric field is given by (Abdu et al., 2003):

$$
E_{z}=U \times B \frac{\Sigma_{F}}{\Sigma_{F}+\Sigma_{E}}
$$

where " $z$ " denotes the vertical axis in altitude, $U$ is thermospheric zonal wind (positive to westward) in the 150 to $300 \mathrm{~km}, B$ is the magnetic field intensity. Under the curlfree condition of the electric field we have

$$
\frac{d E_{z}}{d y}=\frac{d E_{y}}{d z}
$$

where " $y$ " denotes horizontal axis in the zonal direction. This vertical polarization field $\left(E_{z}\right)$ and its longitudinal gradient produce zonal electric field, $E_{y}$, which in turn generates the $\mathbf{E} \times \mathbf{B}$ drift resulting in the evening plasma uplift. This curl-free electric field model has been examined by Eccles (1998) and was well discussed in the recent works (Abdu et al., 2003). Thus the $F$-layer uplift is mainly controlled by the thermospheric zonal (eastward) wind. If the UF-Kelvin wave reaches the ionospheric heights (150$250 \mathrm{~km}$ ) and modulates the zonal wind, its direct manifestation will be seen as the $\mathbf{E} \times \mathbf{B}$ uplift of the $F$ region. In addition to this, the role of the $E$ region dynamo, through modulation in the longitudinal gradient of its integrated conductivity brought about by $E$ layer zonal winds, is also a factor to be considered (Abdu et al., 2006). Direct measurement of the thermospheric wind as a function of height and time would be necessary for further discussion.

The Equatorial spread F occurrence (ESF) calls for a special attention not only from the view point of scientific challenge, but also from that of space technology and space weather application areas. ESF affects radio wave propagations: satellite communications, GPS signal applications, etc. Longitudinal distribution of ESF is monitored by recent satellite observations (Burke et al., 2004; Park et al., 2005). ESF onset time might be an important factor to take in account for forecasting the phenomenon. In this concern we plotted the day to day variation of $h^{\prime} F$ at $2300 \mathrm{UT}$ and the ESF onset time over Fortaleza during the UF-Kelvin wave events. Figure 9 shows day to day plot of $h^{\prime} F$ from day-56 to 76 . The $h^{\prime} F$ varied from $240 \mathrm{~km}$ to $320 \mathrm{~km}$ with a period 


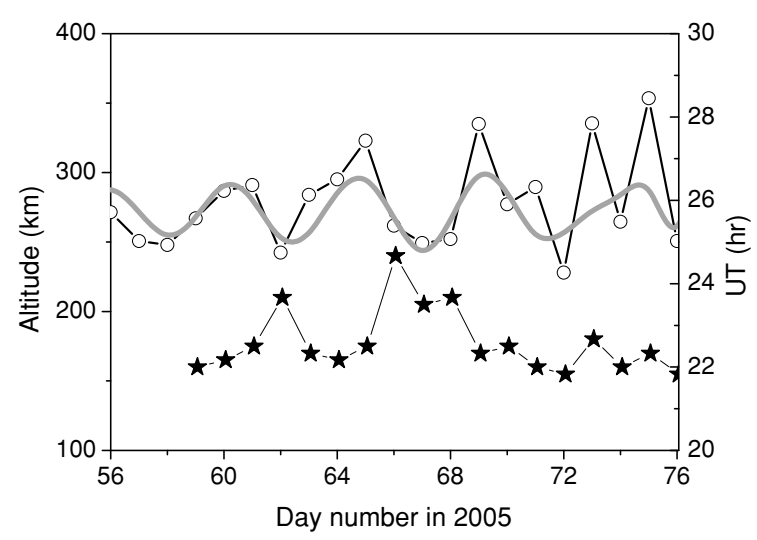

Fig. 9. Day to day variation of the ionospheric $F_{2}$-layer bottom-side virtual height $h^{\prime} F$ at 2300 UT (2000 LT) over Fortaleza (line with circles, legend on left side), 3-5 day filtered harmonic oscillation (smoothed curve), and spread $F$ onset time (star plot, legend on right side). The UF-Kelvin wave was observed from days-60-70.

of 4 days. The spread $F$ onset times taken from the ionogram are also shown (with star marks). During the equinox seasons, the spread $F$ occurs almost every night after sunset, around 2200 UT (1900 LT) (Sobral et al., 2002). However, the onset time was delayed to 2300 UT on the days 62, and 66-68. One can note that when the $h^{\prime} F$ is lower $(\sim 240 \mathrm{~km}$ ) the ESF onset time is later (after $2300 \mathrm{UT})$, and when the $h^{\prime} F$ is higher (above $280 \mathrm{~km}$ ) the ESF is earlier ( 2200 UT). This anti-phased relationship lasted at least for two cycles between the days 60-70. During the second UF-Kelvin wave event (days 190-210), a similar relation was observed. Normally less spread $F$ activity occurs during the period of June-July (Sobral et al., 2002). However, when $h^{\prime} F$ was uplifted above $240 \mathrm{~km}$, due to a passage of the UF-Kelvin wave, the ESF could occur. It seems that the $\mathbf{E} \times \mathbf{B}$ uplifting and ESF onset time are partly modulated by the UF-Kelvin wave.

From Fig. 7 we note that there is a longitudinal modulation in the 3-5-day oscillation amplitude. This suggests us that the influence of UF-Kelvin wave on the ionosphere could be different along the longitudinal zone. Recent observations of zonally modulated equatorial anomaly (Immel et al., 2006) and longitudinal variability of the ionopheric bubble formation (Park et al., 2005) might be in part due to such Planetary scale wave propagation in the ionosphere.

\section{Conclusion}

From the simultaneous measurements of mesospheric wind system and ionospheric parameters in the South American low latitude, we observed a common $\sim 4$-day period oscillation. Based on simultaneous identification of such waves in the TIMED/SABER temperature data we concluded that the observed oscillation are due to a passage of the 3.5 day ultra-fast (UF-) Kelvin wave. The amplitude of the UF-Kelvin wave is significant, $30 \mathrm{~m} / \mathrm{s}$ in the zonal wind at $90 \mathrm{~km}$ height, $10 \mathrm{~K}$ in temperature at $120 \mathrm{~km}, 20 \mathrm{~km}$ of modulation in the $h^{\prime} F$ day to day variation, and $\sim 1 \mathrm{MHz}$ in $f_{\mathrm{o}} F_{2}$. The spread $F$ (ESF) onset time is also modulated by the UF-Kelvin wave with a magnitude of variation of around $2 \mathrm{~h}$. These results suggest us that the UF-Kelvin wave might have an important role in the ionosphere day to day variability.

Acknowledgments. The authors thank those people working at the Cariri and Fortaleza, observation sites. The authors are also grateful to SABER team for providing the temperature data, to NASA and Johns Hopkins University Applied Physics Laboratory and to TIMED Mission team. Wavelet software used in the present work was provided by $\mathrm{C}$. Torrence and $\mathrm{G}$. Compo and is available at URL: http://paos.colorado.edu/research/wavelets/. The present work was partially supported by the Conselho Nacional de Desenvolvimento Científico-CNPq e Tecnológico, CNPq and the Fundação de Apoio à Pesquisa do Estado de São Paulo_-FAPESP.

\section{References}

Abdu, M. A., J. W. MacDougall, I. S. Batista, J. H. A. Sobral, and P. T. Jayachandran, Equatorial evening prereversal electric field enhancement and sporadic $E$ layer disruption: A manifestation of $E$ and $F$ region coupling, J. Geophys. Res., 108(A6), 1254, doi:10.1029/2002JA009285, 2003.

Abdu, M. A., P. P. Batista, I. S. Batista, C. G. M. Brum, A. J. Carrasco, and B. W. Reinisch, Planetary wave oscillations in mesospheric winds, equatorial evening prereversal electric field and spread F, Geophys. Res. Lett., 33, L07107, doi:10.1029/2005GL024837, 2006.

Abdu, M. A., T. Maruyama, I. S. Batista, S. Saito, and M. Nakamura, Ionospheric Responses to the October 2003 super storm: Longitude/ Local Time Effects over Equatorial-Low and Mid-Latitudes, J. Geophys. Res., 2007 (in press).

Brown, G. M. and D. C. Williams, Pressure variations in the stratosphere and ionosphere, J. Atmos. Terr. Phys., 33, 1321-1328, 1971.

Burke, W. J., C. Y. Huang, L. C. Gentle, and L. Bauer, Seasonallongitudinal variability of equatorial plasma bubbles, Ann. Geophys., 22, 3089-3098, 2004.

Chen, P. R., Two-day oscillation of the equatorial ionization anomaly, $J$. Geophys. Res., 97(A5), 6343-6357, 1992.

Eccles, J. V., Modeling investigation of the evening prereversal enhancement of the zonal electric field in the equatorial ionosphere, J. Geophys. Res., 103, 26709-26719, 1998.

Fejer, B. G. and L. Scherliess, Mid-and low-latitude prompt-penetration ionospheric plasma drifts, Geophys. Res. Lett., 25, 3071-3074, 1998.

Forbes, J. M., Planetary Waves in the Thermosphere-Ionosphere System, J. Geomag. Geoelectr., 48, 91, 1996.

Forbes, J. M., Wave coupling between the lower and upper atmosphere: case study of an ultra-fast Kelvin Wave, J. Atmos. Sol.-Terr. Phys., 62, 1603-1621, 2000.

Forbes, J. M. and S. Leveroni, Quasi 16-day oscillation in the ionosphere, Geophys. Res. Lett., 19(10), 981-984, 1992.

Forbes, J. M., S. E. Palo, and X. Zhang, Variability of the ionosphere, J. Atmos. Sol.-Terr. Phys., 62, 685-693, 2000.

Fraser, G., The 5-day wave and ionospheric absorption, J. Atmos. Terr. Phys., 39, 121-124, 1977.

Fukao, S, Coupling Processes in the Equatorial Atmosphere (CPEA): A project overview, J. Meteor. Soc. Jpn., 84A, 1-18, 2006.

Haldoupis, C., D. Pancheva, and N. J. Mitchell, A study of tidal and planetary wave periodicities present in midlatitude sporadic $E$ layers, J. Geophys. Res., 109, A02302, doi:10.1029/2003JA010253, 2004.

Immel, T. J., E. Sagawa, S. L. England, S. B. Henderson, M. E. Hagan, S. B. Mende, H. U. Frey, C. M. Swenson, and L. J. Paxton, Control of equatorial ionospheric morphology by atmospheric tides, Geophys. Res. Lett., 33, L15108, doi:10.1029/2006GL026161, 2006.

Kikuchi, T., H. Lühr, T. Kitamura, O. Saka, and K. Schlegel, Direct penetration of the polar electric field to the equator during $D P 2$ event as detected by the auroral and equatorial magnetometer chains and the EISCAT radar, J. Geophys. Res., 101, 17161-17174, 1996.

Lastovicka, J., Forcing of the ionosphere by waves from below, J. Atmos. Sol.-Terr. Phys., 68, 479-497, 2006.

Lichstein, G. S., J. M. Forbes, M. A. Coll, H. Takahashi, D. Gobbi, and R. A. Buriti, Quasi-3-day Kelvin wave and the $\mathrm{OI}(5577 \mathrm{~A}), \mathrm{OH}(6,2$ Meinel, and O2(0,1) emissions, Geophys. Res. Lett., 29(4), 1043, doi: 10.1029/2001GL031824, 2002.

Lieberman, R. S. and D. Riggin, High resolution Doppler imager observations of Kelvin waves in the equatorial mesosphere and lower thermosphere, J. Geophys. Res., 102(D22), 26117-26130, 1997.

Lima, L. M., P. P. Batista, H. Takahashi, and B. R. Clemesha, Quasi-two- 
day wave observed by meteor radar at $22.7 \mathrm{~S}$, J. Atmos. Sol.-Terr. Phys., 66(6-9), 529-537, 2004.

Miyoshi, Y. and H. Fujiwara, Excitation mechanism of intraseasonal oscillation in the equatorial mesosphere and lower thermosphere, J. Geophys. Res., 111, D14108, doi:101029/2005JD006993, 2006.

Pancheva, D. and I. Lysenko, Quasi-two-day fluctuations observed in the summer $F$ region electron maximum, Bulgarian Geophys. J., XIV, 2, 1988.

Pancheva, D., N. Mitchell, R. Clark, J. Drobjeva, and J. Lastovicka, Variability in the maximum height of the ionospheric F2-layer over Millstone Hill (September 1998-March 2000); influence from below and above, Ann. Geophys., 20(11), 1807-1819, 2002.

Park, J., K. W. Min, V. P. Kim, H. Kil, J.-J. Lee, H.-J. Kim, E. Lee, and D. Y. Lee, Global distribution of equatorial plasma bubbles in the premidnight sector during solar maximum as observed by KOMPSAT-1 and Defense Meteorological Satellite Program F15, J. Geophys. Res., 110, A07308, doi:10.1029/2004JA010817, 2005.

Riggin, D. M., D. C. Fritts, T. Tsuda, T. Nakamura, and R. A. Vincent, Radar observations of a 3-day Kelvin wave in the equatorial mesosphere, J. Geophys. Res., 102(D22): 26141-26158, 1997.

Roettger, J., Equatorial spread $\mathrm{F}$ by electric fields and atmospheric gravity waves generated by thunderstorms, J. Atmos. Terr. Phys., 43, 453-462, 1981.

Russell, J. M., M. G. Mlynczak, L. L. Gordley, J. Tansock, and R. Esplin, An overview of the SABER experiment and preliminary calibration results, Proceedings of the SPIE, 44th Annual Meeting, Denver, Colorado, July 18-23, 3756, p. 277-288, 1999.

Salby, M. L., D. L. Hartmann, P. L. Bailey, and J. C. Gille, Evidence for equatorial Kelvin modes in Nimbus-7 LIMS, J. Atmos. Sci., 41(2), 220235, 1984.

Sobral, J. H. A., M. A. Abdu, H. Takahashi, M. J. Taylor, E. R. Paula, C. J. Zamlutti, and G. L. Borba, A study of the ionospheric plasma bubbles climatology over Brazil, based on 22 years (1977-1998) of OI $630 \mathrm{~nm}$ airglow observation, J. Atmos. Sol.-Terr. Phys., 64(12-14), 1517-1524, 2002.

Sridharan, S., S. Gurubaran, and R. Rajaram, Radar observations of the 3.5-day ultra-fast Kelvin wave in the low-latitude mesopause region, $J$. Atmos. Sol.-Terr. Phys., 64, 1241-1250, 2002.

Takahashi, H., R. A. Buriti, D. Gobbi, and P. P. Batista, Equatorial planetary wave signatures observed in mesospheric airglow emissions, $J$ Atmos. Sol.-Terr. Phys., 64, 1263-1272, 2002.

Takahashi, H., L. M. Lima, C. M. Wrasse, M. A. Abdu, I. S. Batista, D. Gobbi, R. A. Buriti, and P. P. Batista, Evidence on 2-4 day modulation of the equatorial ionosphere $h^{\prime} F$ and mesospheric airglow emission, Geophys. Res. Lett., 32(12), doi:10.1029/2004GRL022318, 2005.

Takahashi, H., C. M. Wrasse, J. Fechine, D. Pancheva, M. A. Abdu, I. S. Batista, L. M. Lima, P. P. Batista, B. R. Clemesha, N. J. Schuch, K. Shiokawa, D. Gobbi, M. G. Mlynczak, and J. M. Russell, Signatures of Ultra Fast Kelvin waves in the equatorial middle atmosphere and ionosphere, Geophys. Res. Lett., 34, L11108, doi:10.1029/2007GL029612, 2007.

Torrence, C. and G. P. Compo, A practical guide to wavelet analysis, Bull. Am. Meteor. Soc., 79, 61-78, 1998.

Vincent, R. A., Long-period motions in the equatorial mesosphere, J. Atmos. Terr. Phys., 55, 1067-1080, 1993.

Younger, P. T. and N. J. Mitchell, Waves with period near 3 days in the equatorial mesosphere and lower thermosphere over Ascension Island, J. Atmos. Sol.-Terr. Phys., 68, 369-378, 2006.

H. Takahashi (e-mail: hisaotak@laser.inpe.br), M. A. Abdu, C. M. Wrasse, J. Fechine, I. S. Batista, D. Pancheva, L. M. Lima, P. P. Batista, B. R. Clemesha, K. Shiokawa, D. Gobbi, M. G. Mlynczak, and J. M. Russell 